\title{
Frequency of Vertebral Endplate Modic Changes in Patients with Unstable Lumbar Spine and Its Effect on Surgical Outcome
}

\author{
Seyyed Mohammad Ghodsi, Reza Rouhani, Sina Abdollahzade, \\ Masoud Khadivi, Morteza Faghih Jouibari \\ Department of Neurosurgery, Shariati Hospital, Tehran University of Medical Sciences, Tehran, Iran
}

\begin{abstract}
Study Design: Prospective cohort study.
Purpose: In this study, we investigated the frequency of vertebral endplate Modic changes (MCs) and their effects on surgical outcomes in patients with unstable lumbar spines.

Overview of Literature: Signal changes in endplates have been classified into three types by Modic. The prognostic role of MCs has been investigated in various spinal disorders.

Methods: A series of 70 patients with clinical and radiographic unstable lumbar spine were included in the study. Endplate signal intensity was determined according to Modic classification. All patients underwent instrumented posterolateral fusion. Functional evaluation was made using the visual analog scale (VAS) and Oswestry disability index (ODI).

Results: Eighteen patients (26\%) had normal endplate intensity, 31 patients (44\%) had MC type I, 20 patients (28\%) had MC type II, and one patient (1.4\%) had MC type III. Pain level VAS and ODI decreased significantly from the preoperative evaluation to the sixmonth and one-year postoperative evaluations. The surgical outcome (VAS and ODI) was not significantly different between the various types of MC.

Conclusions: Posterolateral fusion is an effective treatment in patients with unstable lumbar spines. MC do not have a significant effect on the surgical outcome of these patients.
\end{abstract}

Keywords: Intervertebral disc degeneration; Spinal fusion

\section{Introduction}

Signal intensity changes of vertebral endplates and subchondral bone are often observed in the magnetic resonance imaging (MRI) of patients with spinal degenerative disorders and have been given increasing attention in recent years. In 1988, Modic summarized these changes and classified them into three types [1,2]: Modic change
(MC) type I refers to an edema-like signal intensity (hypointense T1 and hyperintense T2 signal), MC II refers to fat-like signal intensity (hyperintense T1 and isointense or slightly hyperintense T2), and MC III refers to a sclerosislike signal intensity (hypointense $\mathrm{T} 1$ and $\mathrm{T} 2$ ). There are numerous studies evaluating the prognostic importance of MCs in different spinal disorders [3-5].

Segmental instability is a common cause of low back

Received Jan 25, 2015; Revised Feb 22, 2015; Accepted Mar 7, 2015

Corresponding author: Morteza Faghih Jouibari

Department of Neurosurgery, Shariati Hospital, Tehran University of Medical Sciences,

Jalal Al Ahmad Street, Amir Abad Avenue, Tehran, Iran

Tel: +98-21-8822-0040, Fax: +98-21-8822-0040, E-mail: mortezafaghihj@yahoo.com 
pain that has been regarded as a factor in developing MC [6]. It can cause the disruption of endplates and degeneration of the adjacent bone marrow. The standard of care for the surgical treatment of degenerative lumbar spine instability has long been spinal fusion.

The aim of this study was to investigate prevalence of MC in patients with radiographically unstable lumbar spines and its correlation with the severity of preoperative pain and outcome after posterolateral fusion. Such information could be used in the decision-making process prior to surgery.

\section{Materials and Methods}

From July 2010 to August 2013 a consecutive series of patients affected by chronic low back pain due to single-level degenerative lumbar instability and lasting over three or more months of continuous conservative care were recruited in our study. Sagittal segmental instability was measured using lateral radiographs at the extension and flexion positions. The amount of sagittal translation was obtained as the difference of the displacement between flexion and extension. Segmental angulation was also measured as the difference of the intervertebral angles from extension to flexion. Based on White and Panjabi method [7], translation $\geq 3 \mathrm{~mm}$ or angulation $\geq 10^{\circ}$ were defined as instability. All patients underwent single-level pedicular fixation and posterolateral fusion.

\section{Data collection}

Preoperative MRI scans were evaluated by a neuroradiologist who was blinded to patient information other than the patient's name, sex, and age. MCs were evaluated according to the standardized evaluation protocol, "Nordic Modic Consensus Group classification" [8]. For each patient, the MRI findings were characterized into four groups; no MC, MC type I, MC type II, or MC type III.

The patients filled in the visual analog scale (VAS, 0-100 $\mathrm{mm}$ ) and Oswestry disability index (ODI, $0-100)$ questionnaires before surgery, and at six months and one year post surgery.

\section{Statistics}

Continuous variables are expressed as mean \pm standard deviations. Categorical data are presented as frequencies and percentages. Differences of VAS and ODI between subgroups were analyzed by means of $t$-tests. Statistical analyses were carried out with the SAS ver. 9.1 (SAS Institute Inc., Cary, NC, USA).

\section{Results}

During the observation period, 70 patients who met the inclusion criteria were admitted to our center and underwent pedicular fixation and posterolateral fusion. The mean patient age on admission was $58 \pm 14$ years (range, $15-74$ years); 53 patients (76\%) were female and $17 \mathrm{pa}$ tients $(24 \%)$ were male. Segmental instability involved the L2-L3 level in 5 patients, L3-L4 level in 7 patients, L4-L5 level in 44 patients, and L5-S1 level in 14 patients. Eighteen patients $(26 \%)$ had normal endplate intensity in the unstable segment. MCs were found in 52 patients (74\%). Thirty-one patients (44\%) had MC type I, 20 patients (28\%) had MC type II, and 1 patient (1.4\%) had MC type III.

In L2-L3 level patients, 1 had no MC, 2 had type I, and 2 had type II. In L3-L4 level patients, 2 had no MC, 4 had type I and 1 had type II. In L4-L5 level patients, 9 had no MC, 21 had type I, 13 had type II and 1 had type III. In L5-S1 level patients, 6 had no MC, 4 had type I and 4 had type II.

The mean intensity of pain according to the VAS obtained prior to surgical intervention was $6.1 \pm 3$.4. Pain level decreased progressively by the sixth month (4.2 \pm 3.9$)$ and first year (3.8 \pm 3.3$)$ after surgery. Clinical outcomes evaluated using ODI decreased significantly from the preoperative evaluation (mean, 43; range, 10-66) to the sixth month (mean, 20.3; range, 0-26) and first year (mean, 16.2 ; range, $0-58)$ postoperative evaluations $(p<0.001)$. There was no association between the type of MC and VAS before surgery. Also, clinical outcomes (VAS and ODI) six months and one year postoperatively were not significantly different between the various types of MC.

\section{Discussion}

Instability is one of the main causes of low back pain and a common reason for surgical treatment. Decreased structural integrity of intervertebral discs $[9,10]$, ligaments, and facets $[11,12]$ is responsible for the genesis of spinal instability. Degenerative changes can cause instability by loss of disc height, posterior facet joint subluxation, and 
abnormal patterns of motion $[1,13]$. So, it is a common problem in old age, and most of our patients were older. The number of female patients were three times greater than the number of male patients in the present study, which may be related to their susceptibility to degenerative changes, hormonal status, or lifestyle [14-17].

Abnormal MRI signals in endplates have been classified to Modic types. Biomechanical [18] and biochemical [1922] causes, are possible mechanisms in the pathogenesis of MC [23]. Instability as a biomechanical abnormality can predispose the affected segments to MC. There are numerous studies [3-5] investigating the prevalence of MC in patients with low back pain and its effect on surgical outcomes after fusion. We specifically studied a subgroup of patients with lumbar instability and evaluated the prognostic role of MC. MCs were found in 74\% of our patients, which is higher than most studies investigating patients with nonspecific low back pain $[24,25]$. This underlines the probable role of instability in the pathogenesis of MCs. On the other hand, 25\% of patients did not show $\mathrm{MC}$ in their respective unstable segments. So, instability can happen without MC and an abnormal signal in the endplates is not a prerequisite for segmental instability. It seems informative to design another study to evaluate any correlation between the severity of instability and prevalence of MC.

Low back pain, which is aggravated by movement, is the typical presentation of unstable lumbar spine. Different mechanisms can be responsible for pain generation in lumbar instability, such as neural compression, traction and tear of spinal ligaments, spasm in paravertebral muscles, inflammation of facet joints, and pathologic changes in the disc and endplates [26-28]. MCs, which reflect endplate abnormalities, have been considered to be risk factors for back pain in some studies $[18,29,30]$. In our study, the severity of preoperative pain was not higher in patients with MCs or in type I than in type II. We think that abnormal changes of endplates in unstable segments does not play a prominent role among other more powerful mechanisms of pain generation.

Arthrodesis is the preferred method of treatment in most patients with unstable lumbar spines. It can improve symptoms by alleviating abnormal motion and reducing distress on endplates, ligaments, and neural elements. In our study, posterolateral fusion significantly improved symptoms according to the VAS and ODI. There was no significant difference in outcome among patients with
MC type I and type II. It can be concluded that spinal fusion improves symptoms effectively by restricting the abnormal segmental movement and probably by reducing the repeated injury to ligaments, paravertebral muscles, and neural structures in different types of MC. Endplate changes do not play a notable role in predicting surgical outcome.

\section{Conclusions}

Posterolateral fusion is an effective treatment in patients with radiographically unstable lumbar spine regardless of Modic type. MCs do not have a significant effect on the severity of preoperative pain or the surgical outcome of these patients.

\section{Conflict of Interest}

No potential conflict of interest relevant to this article was reported.

\section{References}

1. Modic MT, Steinberg PM, Ross JS, Masaryk TJ, Carter JR. Degenerative disk disease: assessment of changes in vertebral body marrow with MR imaging. Radiology 1988;166:193-9.

2. Modic MT, Masaryk TJ, Ross JS, Carter JR. Imaging of degenerative disk disease. Radiology 1988;168:17786.

3. Jensen RK, Leboeuf-Yde C, Wedderkopp N, Sorensen JS, Jensen TS, Manniche C. Is the development of Modic changes associated with clinical symptoms? A 14-month cohort study with MRI. Eur Spine J 2012; 21:2271-9.

4. Keller A, Boyle E, Skog TA, Cassidy JD, Bautz-Holter E. Are Modic changes prognostic for recovery in a cohort of patients with non-specific low back pain? Eur Spine J 2012;21:418-24.

5. Sorlie A, Moholdt V, Kvistad KA, et al. Modic type I changes and recovery of back pain after lumbar microdiscectomy. Eur Spine J 2012;21:2252-8.

6. Toyone T, Takahashi K, Kitahara H, Yamagata M, Murakami M, Moriya H. Vertebral bone-marrow changes in degenerative lumbar disc disease. An MRI study of 74 patients with low back pain. J Bone Joint Surg Br 1994;76:757-64. 
7. White AA III, Panjabi MM. Clinical biomechanics of the spine. 2nd ed. Philadelphia: Lippincott Williams \& Wilkins; 1990.

8. Jensen TS, Sorensen JS, Kjaer P. Intra- and interobserver reproducibility of vertebral endplate signal (modic) changes in the lumbar spine: the Nordic Modic Consensus Group classification. Acta Radiol 2007;48:748-54.

9. Kirkaldy-Willis WH, Farfan HF. Instability of the lumbar spine. Clin Orthop Relat Res 1982;(165):11023.

10. Fujiwara A, Lim TH, An HS, et al. The effect of disc degeneration and facet joint osteoarthritis on the segmental flexibility of the lumbar spine. Spine (Phila Pa 1976) 2000;25:3036-44.

11. Haher TR, O’Brien M, Dryer JW, Nucci R, Zipnick R, Leone DJ. The role of the lumbar facet joints in spinal stability. Identification of alternative paths of loading. Spine (Phila Pa 1976) 1994;19:2667-70.

12. Fujiwara A, Tamai K, An HS, et al. The relationship between disc degeneration, facet joint osteoarthritis, and stability of the degenerative lumbar spine. J Spinal Disord 2000;13:444-50.

13. Gruber HE, Hanley EN Jr. Recent advances in disc cell biology. Spine (Phila Pa 1976) 2003;28:186-93.

14. Wang YX, Griffith JF. Menopause causes vertebral endplate degeneration and decrease in nutrient diffusion to the intervertebral discs. Med Hypotheses 2011;77:18-20.

15. Wang YX, Griffith JF, Zeng XJ, et al. Prevalence and sex difference of lumbar disc space narrowing in elderly chinese men and women: osteoporotic fractures in men (Hong Kong) and osteoporotic fractures in women (Hong Kong) studies. Arthritis Rheum 2013;65:1004-10.

16. Teraguchi M, Yoshimura N, Hashizume H, et al. Prevalence and distribution of intervertebral disc degeneration over the entire spine in a populationbased cohort: the Wakayama Spine Study. Osteoarthritis Cartilage 2014;22:104-10.

17. Manson NA, Goldberg EJ, Andersson GB. Sexual dimorphism in degenerative disorders of the spine. Orthop Clin North Am 2006;37:549-53.
18. Modic MT. Modic type 1 and type 2 changes. J Neurosurg Spine 2007;6:150-1.

19. Albert HB, Kjaer P, Jensen TS, Sorensen JS, Bendix T, Manniche C. Modic changes, possible causes and relation to low back pain. Med Hypotheses 2008;70: 361-8.

20. Crock HV. A reappraisal of intervertebral disc lesions. Med J Aust 1970;1:983-9.

21. Crock HV. Internal disc disruption. A challenge to disc prolapse fifty years on. Spine (Phila Pa 1976) 1986;11:650-3

22. Braithwaite I, White J, Saifuddin A, Renton P, Taylor BA. Vertebral end-plate (Modic) changes on lumbar spine MRI: correlation with pain reproduction at lumbar discography. Eur Spine J 1998;7:363-8.

23. Zhang YH, Zhao CQ, Jiang LS, Chen XD, Dai LY. Modic changes: a systematic review of the literature. Eur Spine J 2008;17:1289-99.

24. Villarreal-Arroyo M, Mejia-Herrera JC, LariosForte MC. Incidence of Modic degenerative changes in patients with chronic lumbar pain at Monterrey Regional ISSSTE Hospital. Acta Ortop Mex 2012;26: 180-4.

25. Jensen TS, Karppinen J, Sorensen JS, Niinimaki J, Leboeuf-Yde C. Vertebral endplate signal changes (Modic change): a systematic literature review of prevalence and association with non-specific low back pain. Eur Spine J 2008;17:1407-22.

26. Macnab I. The traction spur: an indicator of segmental instability. J Bone Joint Surg Am 1971;53:663-70.

27. Lettin AW. Diagnosis and treatment of lumbar instability. J Bone Joint Surg Br 1967;49:520-9.

28. Morgan FP, King T. Primary instability of lumbar vertebrae as a common cause of low back pain. J Bone Joint Surg Br 1957;39:6-22.

29. Albert HB, Manniche C. Modic changes following lumbar disc herniation. Eur Spine J 2007;16:977-82.

30. Kuisma M, Karppinen J, Niinimaki J, et al. Modic changes in endplates of lumbar vertebral bodies: prevalence and association with low back and sciatic pain among middle-aged male workers. Spine (Phila Pa 1976) 2007;32:1116-22. 